\title{
Oral contraception and benign breast diseases
}

\author{
A. Carbonaro. L. Ciotta, M. Stracquadanio, C. Formuso. M. R. Giunta. A. D. Agati, V. Leanza, \\ T. T. Giannone, Mayada Chammas, Fawzi Chammas, C. Pafumi*, G. Zarbo
}

Dept of Obst and Gyn University of Catania, Italy

Via Torre del Vescovo 2, Catania, Italy

American University of Beirut- Lebanon

\section{Email address:}

pafumi@unict.it (C. Pafumi)

\section{To cite this article:}

A. Carbonaro, L. Ciotta, M. Stracquadanio, C. Formuso, M. R. Giunta, A. D. Agati, V. Leanza, T. T. Giannone, Mayada Chammas, Fawzi Chammas, C. Pafumi, G. Zarbo. Oral Contraception and Breast Diseases. American Journal of Nursing Science. Vol. 1, No. 1, 2012, pp. 1-4. doi: 10.11648/j.ajns.20120101.11

\begin{abstract}
Objective: Benign breast disease includes a wide spectrum of lesions different for histology and natural history, whose association with oral contraceptives is of great interest because there are no univocal results in literature. Subjects and Methods: The purpose of our study is to assess the relationship between women who used long- term estro-progestin (for at least 12 consecutive months up to a maximum of 60 months) and the develop of benign breast disease comparing with a case- control group composed by patients with benign breast disease, non-users of oral contraceptives. The study included 263 women attending, from 2009 to 2012, the Gynecological Endocrinology and Ultrasounds outpatients of our Department, who used oestroprogestative pills for Contraception, treatment of acne, hirsutism and treatment of dysmenorrheal and a control group of 200 patients with benign breast disease, non-users of Oral Contraceptives.Results: According to recent trials we did not observe statistically significant morphological and anatomical alterations of the breast in the group treated with estrogen-progestin therapy in comparison with the control group. Conclusion: If the woman presents a nodular breast mass during estro-progestin therapy she should be evaluated ultrasonographically to assess if the formation grows. If there is an increase in volume of the mass the patient should suspend the therapy.
\end{abstract}

Keywords: Oral Contraception, Benign Breast Disease, Breast Cancer, Ultrasound Examination

\section{Introduction}

Treatment with estrogen-progestin hormone is the most used therapy by women in reproductive age, both as contraception and for hormonal diseases, such as Polycystic Ovary Syndrome. Particular attention should be paid to the effects of Oral Contraceptives on the breast, because it is well known that the benign breast disease (PBM) is related to hormonal changes, for the peculiar effects that steroid hormones have on cell metabolism and breast structure. Estrogens play their action on the main ductal system, with differences in sensitivity: for example, it is assumed that the larger ducts are more responsive than the intralobular ducts; estrogens, furthermore, promote the differentiation and development of the galactophore system, increase the mitotic activity of the cylindrical cells and induce hyalinization of the connective tissue. Similarly, progesterone acts on the development and function of the lobule-alveolar system, and, with estrogen, induce the growth of the grapes.[1]Numerous data indicate the presence of high le- vels of ovarian and adrenal androgens in patients with benign breast disease; it has been demonstrated that some of them (DEA and DEA-S) have anantagonistic action to the progesterone one. Therefore, we can hypotize a direct or mediated effect of C.O. catabolites on the breast and on benign mastopathy.[2-5]Fibroadenoma is a benign nodule, solid, round, painful during menstruation, which originates from the mammary grapes, so it isn't usually present in the menopause, a time when the breast regresses. The mastopathy is a phase of evolution of the glandular breast tissue, not a disease. It 'a condition that may be associated with cancer risk. It can occur with different aspects of proliferative tissues involved. Sometimes even with atypia. You can find non-proliferative lesions, proliferative lesions without atypia, atypical hyperplasia.Breast pain (mastodynia) is by far the most common breast symptom that leads adult female to breast examination. May be affected by the menstrual cycle, and especially pronounced in the premenstrual phase.The most interested part is the super-outer quadrant and the gland is usually place of small multipleknottiness 
at palpation, while the mammography shows only the presence of a fibrocystic mastopathy. Sometimes it can be caused by inflammatory processes, eg. mastitis, galattoforitis, etc.. expecially during lactation.Regarding clinical data, epidemiological studies and especially the only prospective placebo-controlled study (The Women's Health Initiative) demonstrate an increased risk under combined estrogen/progesterone, but not under estrogen-only therapy.[6] Besides, there are no unique data in the literature about the use of oral contraceptives and benign breast diseases.

\section{Materials and Methods}

The aim of our study was to assess the relationship between women who used long- term estro-progestin (for at least 12 consecutive months up to a maximum of 60 months) and the develop of benign breast disease comparing with a case- control group composed by patients with benign breast disease, non-users of oral contraceptives. The study included 263 women attending, from 2009 to 2012, the Gynecological Endocrinology and Ultrasounds outpatients of our Department.

The patients referred to the clinic required (Graph 1):

a) Contraception (27\%);

b) Treatment of acne (18\%);

c) Therapy of hirsutism (22\%);

d) Treatment of dysmenorrhea (1.7\%).

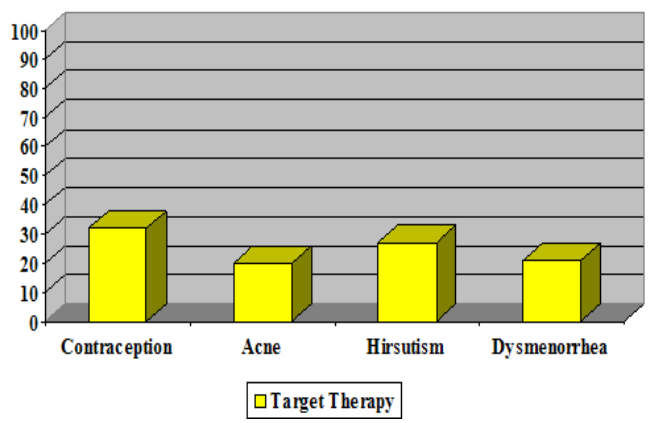

Figure 1. Target therapy with oestroprogestative pills.

The benign breast diseases identified, in order of incidence, were as follows (Graph 2):

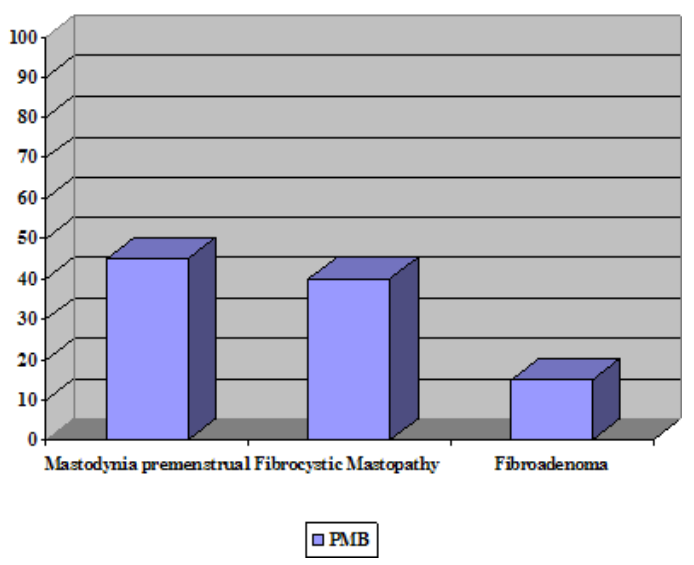

Figure 2. Breast benign diseases.
1) Mastodynia premenstrual (31\%);

2) Fibrocystic Mastopathy (28\%);

3 ) Fibroadenoma, fibrosis and cysts $(12 \%)$.

The methods used for the diagnosis and for monitoring the PBM were as follows:

1) Clinical examination;

2) Ultrasound;

3) By needle aspiration cytology;

5) Mammography.

The study group (Group A, 263 women) used estrogenprogestin for at least 12 consecutive months up to a maximum of 60 months, with an average intake of $28+/-4$ months. The control group (Group B) was represented by 200 patients with PBM, non-users of Oral Contraceptives. The percentage distribution of the type of PBM was identical to that present in Study Group.EP formulations used were:

1) ethinyl-estradiol (EE) $20 \mathrm{mcg}+$ drospirenone $3 \mathrm{mg}$ $(12 \%)$

2) $\mathrm{EE} 30 \mathrm{mcg}$ + Drospirenone $3 \mathrm{mg}(10 \%)$

3) EE $30 \mathrm{mcg}+$ Chlormadinone $2 \mathrm{mg}(13 \%)$

4) $\mathrm{EE} 30 \mathrm{mcg}+$ Gestodene $0.075 \mathrm{mg}(15 \%)$

\section{Results}

In our study we did not observe statistically significant change state morphology and anatomy of the breast in the group receiving estrogen-progestin therapy (Group A) compared with the control group (Group B).No significant differences has been reported in reference to the type and dosage of the combination of estrogen-progestogen used.The only data suggestive and worthy of further study (although not statistically significant as a percentage) were as follows:

1) Subjective reduction of mastodynia (density range 0 to 10), after the protracted assumption $\mathrm{CO}$ for at least 36 months (Group A vs Group B: P <0.09) (Graph 3).

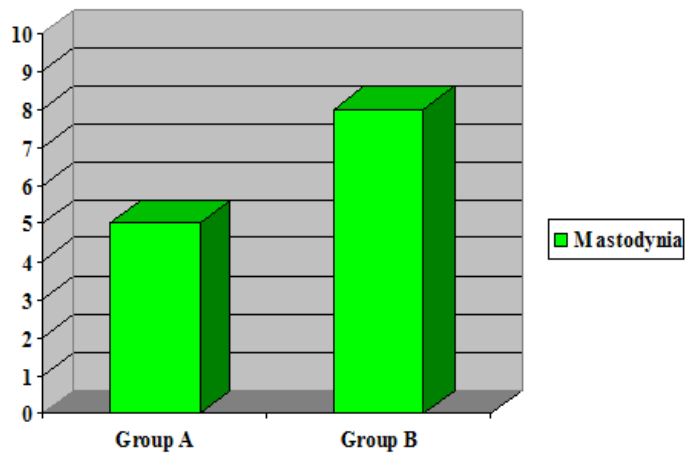

Figure 3. Subjective reduction of mastodynia.

\begin{tabular}{ll}
\hline & Intensity of Mastodynia \\
\hline Group A & 5 \\
Group B & 8 \\
\hline
\end{tabular}

2) Unchanged the clinical picture and the incidence of 
diseases like the fibroadenomas and focal cystic changes, as well as the more general fibrous mastopathy.

\section{Discussions}

Our study confirms what has already been reported by previous clinical trials that showed a response of neutrality or of modest improvement induced by hormonal contraceptives on benign breast disease. This is conceivable as a consequence of the reduced and balanced combination of existing hormonal preparations, which, by determining a hormonal environment favorable, rebalance a framework endocrine baseline altered.[7] Besides, the use of HRT does not appear to influence the clinical pattern of benign breast disease in postmenopausal women, although enlargement of pre-existing cysts or fibroadenomas has been sometimes reported.[8]Instead, breast cancer seems to be positively dependent on prolonged oral contraceptive use.[9]Oral contraceptives probably promote the growth of already existing cancer, they are probably promoters not initiators of breast cancer.[10]

Of course, there is consistent evidence that women diagnosed with benign breast disease (BBD) are at an increased risk of breast cancer compared to women without a history of benign breast disease.[11-12] Though BBD encompasses a number of histologic subtypes, women with such a diagnosis have double the risk of breast cancer compared to women without.[13-14] Increased morphologic data have refined our ability to estimate a woman's risk of subsequent breast cancer.[15] Compared to women without benign breast disease or with nonproliferative lesions, the risk of developing breast cancer increases 1.5 to two-fold for women with proliferative changes without atypia and three to five-fold for women with atypical hyperplasia[1617].

Besides, it was discovered that hormonal contraceptives (HC) and hormone replacement therapy (HRT) decreases the age when breast cancer was first diagnosed.[18]

Oral contraceptive (OC) use has been linked to increased risk of breast cancer, largely on the basis of studies conducted before 1990.[19] In the Case-Control Surveillance Study, a US hospital-based case-control study of medication use and cancer, the authors assessed the relation of $\mathrm{OC}$ use to breast cancer risk among 907 case women with incident invasive breast cancer (731 white, 176 black) and 1,711 controls (1,152 white, 559 black) interviewed from 1993 to 2007 . They evaluated whether the association differed by ethnicity or tumor hormone receptor status. After control for breast cancer risk factors, the multivariable odds ratio for 1 year or more of $\mathrm{OC}$ use, relative to less than 1 year of use, was 1.5 (95\% confidence interval: 1.2 , 1.8). The estimates were similar within age strata $(<50$ years and $\geq 50$ years). The odds ratios were larger for use within the previous 10 years, long-duration use, and black ethnicity, but these differences were not statistically significant. [19] The association of OC use with breast cancer risk did not differ according to the estrogen or progestogen receptor status of the tumor.[20-21] These results suggest that $\mathrm{OC}$ use is associated with an increased risk of breast cancer diagnosed in recent years.

A recent study states that breast cancer risk did not vary significantly by OC formulation, and no formulation was associated with a significantly increased breast cancer risk,[22] while in another study was found that current use of triphasic preparations containing levonorgestrel as the progestin is associated with higher risk than use of other formulations.[23]In our study we did not observe statistically significant change in morphological and anatomical breast characteristics in progestin therapy group (Group A) compared with the control group (Group B)

\section{Conclusions}

In conclusion, some of the benefits associated with regular and prolonged use of oral contraceptives are a direct consequence of the association of steroid receptors progestogens on the breast. Focal benign breast changes, such as fibroadenoma, do not undergo volumetric changes different than their natural history. Therefore, while not considering unanimously oral contraceptives a therapeutic measure for benign mastopathy, it can be asserted that this does not alters the incidence and prevalence of the same.

Nevertheless, it is good practice to monitor by ultrasound examination for the presence of nodular breast masses during treatment with estrogen-progestin at least every two years, to exclude a possible increase in volume of such formations.If there was a nodule larger than the initial period of treatment, it is recommended the suspension of the oral contraceptive.

Furthermore, in some studies has been confirmed the presence of a positive correlation between the prolonged use of estrogen-progestin contraception and the reduction of the risk of proliferative forms of mastopathy like hyperplasia without atypia, and an increase of the same for all forms of mastopathy with atypia.

\section{Acknowledgments}

Valentina Pafumi has carried out English language editing for this article.

\section{References}

[1] Pastides H., Kelsey JI, Livolsi VA et al.. Oral contraceptive use and fibrocystic breast disease with special reference to its histopathology. J Natl Cancer Inst. 1983 Jul;71(1):5-9.

[2] Franceschi S., La Vecchia C., Parazzini F, Talamini R.. An epidemiological study on the relationship between oral contraceptives and benign breast disease. Contracept-fertil-sex. 14/2 (125-129). 1986.

[3] Ragni N, Boccardo E, Viglino S, Larosa E. Oral contraception and breast pathology. Acta Eur Fertil. 1981 Jun;12(2):141-63. 
[4] Hsieh CC, Crosson AW, Walker AM, Trapido EJ, MacMahon B. Oral contraceptive use and fibrocystic breast disease of different histologic classifications. J Natl Cancer Inst. 1984 Feb;72(2):285-90.

[5] Rohan TE, L'Abbé KA, Cook MG. Oral contraceptives and risk of benign proliferative epithelial disorders of the breast. Int J Cancer. 1992 Apr 1;50(6):891-4.

[6] Ruan X, Seeger H, Mueck AO. Breast cancer risk during hormone therapy: experimental versus clinical data. Minerva Endocrinol. 2012 Mar;37(1):59-74.

[7] Franchi F., Gioffrè WR, Calvelli P., et al.. Contraccezione orale e mastopatie benigne. Incontri di Endocrinologia Riproduttiva. 1994, Giu 5; 507-510.

[8] Gadducci A, Guerrieri ME, Genazzani AR. Benign breast diseases, contraception and hormone replacement therapy. Minerva Ginecol. 2012 Feb;64(1):67-74.

[9] Iatrakis G, Iavazzo C, Zervoudis S, Koumousidis A, Sofoudis C, Kalampokas T, Salakos N. The role of oral contraception use in the occurrence of breast cancer. A retrospective study of 405 patients. Clin Exp Obstet Gynecol. 2011;38(3):225-7.

[10] Veljković M, Veljković S. The risk of breast cervical, endometrial and ovarian cancer in oral contraceptive users. Med Pregl. 2010 Sep-Oct;63(9-10):657-61.

[11] Geoffrey C.Kabat, Joan G.Jones, Neal Olson, Abdissa Negassa, Chaterine Duggan, Mindy Ginsberg, Rita A. Candel, Andrew G.Glass, Thomas E.Rohan. A multi-center prospective cohort srudy of benign breast disease and risk of subsequent breast cancer. Cancer Causes Control, 2010 June; 21(6):821-828.

[12] Hai-Lin Park, Sea-Hyun Kwon, So Yong Chang, Jung Yin Huh, Ji Young Kim, Jeong Yun Shim, Yoon Hee Lee. LongTerm Follow-up result of benign phyllode tumor of the breast diagnosed and excised by ultrasound-guided vacuumassisted breast biopsy. J Breast Cancer, 2012 June 15(2):224-229.

[13] Kròlik M, Milnerowicz H. The effect of using estrogens in the light of scientific research. Adv Clin Exp Med, 2012 JulAug; 21(4):535-43.

[14] Garad R, McNamee K, Bateson D, Harvey C. Update on contraception. Aust Nurs J, 2012 Oct, 20(4):34-7.
[15] Rin Yamaguchi, Shin-ichi Tsuchiya, Takashi Koshikawa, Toshiro Yokoyama, Kuniko Mibuchi, Yasuhide Nonaka, Sonoe Ito, Hidejiro Higuchi, Mariko Nago, Koichi Higaki, Jiro Watanabe, Masayoshi Kage, Hirohisa Yano. Evaluation of inadequate, indeterminate, false-negative and falsepositive cases in cytological examinationfor breast cancer according to histological type. Diagn Pathol 2012, 7-53.

[16] Rulla M. Tamimi, Bernard Rosner, Graham Colditz. Evaluation of a breast cancer risk prediction model expanded to include category of prior benign breast disease lesion. Cancer, 2010 November 1; 116(21):4944-4953.

[17] Kristina M. Blackmore, Jody Wong, Julia A. Knight. A cross sectional study of different patterns of oral contraceptive use among premenopausal woman and circulatin IGF-1: implications for disease risk. BMC Womens Health, 2011, $11-15$.

[18] Habánová M, Svikruhová J, Sláviková E. Hormonal contraceptives and their relationship to breast cancer. Klin Onkol. 2010;23(6):428-32.

[19] Lynn Rosenberg, Yuging Zhang, Patricia F. Coogan, Brian L. Strom, Julie R. Palmer. A Case-Control Study of Oral Contraceptive Use and Incident Breast Cancer. Am J Epidemiol 2009 February $15 ; 169(4): 473-479$.

[20] Lori C.Sakoda, Christie R.Blackston, Jennifer A. Doherty, Roberta M. Ray, Ming Gang Lin, Dao Li Gao, Helge Stasberg, Ziding Feng, David B. Thomas, Chu Chen. Selected estrogen receptor 1 and androgen receptor gene polymorphisms in relation to risk of breast cancer and fibrocystic breast conditions among Chinese women. Cancer Epidemiol, 2011 February 35(1): 48-55.

[21] Lynn Rosenberg, Deborah A. Boggs, Lauren A.Wise, Lucile L.Adams-Campbell, Julie R. Palmer. Oral contraceptive useand estrogen/progesterone receptor negative breast cancer among African American Women. Cancer Epidemiol Biomarkers Prev. 2010 August; 19(8): 2073-2079.

[22] Marchbanks PA, Curtis KM, Mandel MG, et all. Oral contraceptive formulation and risk of breast cancer. Contraception. 2012 Apr;85(4):342-50. Epub 2011 Sep 28.

[23] Hunter DJ, Colditz GA, Hankinson SE, et all. Oral contraceptive use and breast cancer: a prospective study of young women. Cancer Epidemiol Biomarkers Prev. 2010 Oct;19(10):2496-502. 